\title{
Programa de Educação pelo Trabalho para a Saúde da Universidade de São Paulo (Campus Capital): o olhar dos tutores
}

The Education Program of Work for Health of the University of São Paulo (capital campus): the viewpoint of the tutors

Graciela Soares Fonsêca ${ }^{1}$

Simone Rennó Junqueira ${ }^{1}$

${ }^{1}$ Faculdade de Odontologia, Universidade de São Paulo. Av. Professor Lineu Prestes 2227. Cidade Universitária. 05.508-000 São Paulo SP Brasil.

gracielafonseca@usp.br

\begin{abstract}
In order to bring about positive changes in the education process of health professionals, the Ministries of Health and Education established the Education Program of Work for Health in 2008. The study aimed to achieve the consensus of a group of experts about the Program established at the University of São Paulo, Capital Campus, Brazil. The subjects of the study were the tutors who joined the program in 20102012. A qualitative approach was used based on the Delphi Technique. Among the data collected, tutors believe the program provides benefits to teaching practices and contributes to qualification of professionals involved in health services, and offers improvements for training in the health area. From the subjects' point of view, the tutors are the link between academia and the health services and the instructors are critical to ensure the effectiveness of activities. The staging of regular meetings and seminars help in the process. The main limitations are the lack of explicit commitment shown by some students and the high workload of undergraduate courses.
\end{abstract}

Key words Education, Human resources training, Qualitative research, Delphi technique
Resumo No sentido de gerar mudanças positivas no processo de formação em Saúde, os Ministérios da Saúde e da Educação instituíram, em 2008, o Programa de Educação pelo Trabalho para a Saúde (PET-Saúde). O estudo se propôs a obter o consenso de um grupo de conhecedores em potencial sobre o Programa, implementado na Universidade de São Paulo, Campus Capital. Os sujeitos do estudo foram os tutores que integraram a proposta no período 2010-2012. Utilizou-se uma abordagem qualitativa, auxiliada pela técnica Delphi. Dentre os pontos levantados, os tutores acreditam que o Programa proporciona benefícios para a atuação docente e contribui para a qualificação dos profissionais inseridos nos serviços de saúde, além de oferecer melhorias para a formação na área da saúde. Na opinião dos sujeitos, os tutores representam o elo entre a academia e os serviços de saúde e os preceptores são de grande importância para garantir a efetividade das atividades. O planejamento de reuniões regulares e seminários auxiliam no processo. Os principais limites explicitados foram a falta de comprometimento manifestada por alguns estudantes e a alta carga horária dos cursos de graduação.

Palavras-chave Educação, Formação de recursos humanos, Pesquisa qualitativa, Técnica delfos 


\section{Introdução}

Em direção contrária aos preceitos do Sistema Único de Saúde (SUS), existe um descompasso entre a formação de recursos humanos e as necessidades dos serviços de saúde ${ }^{1}$. Torna-se inerente a necessidade de se buscar o engendramento de novas relações de responsabilidade e compromisso entre as instituições de ensino e o SUS, de modo a favorecer a cogestão dos processos, para que realmente se alcance mudanças significativas na formação em saúde ${ }^{2}$. A articulação das Instituições de Ensino Superior (IES) com o sistema público de saúde repercute e é imprescindível para a formação de recursos humanos na perspectiva do SUS $^{3}$.

Uma forma de incentivar a inserção de IES nas unidades de saúde foi a criação do Programa de Educação pelo Trabalho para a Saúde (PETSaúde). O Programa foi instituído em 2008, no âmbito dos Ministérios da Saúde e da Educação, destinado a fomentar grupos de aprendizagem tutorial inseridos na Estratégia Saúde da Família $(\mathrm{ESF})^{4}$. Caracteriza-se como uma das ações direcionadas ao fortalecimento da Atenção Primária em Saúde (APS), em conformidade com as necessidades do SUS e como fio condutor da interação ensino-serviço-comunidade, eixo básico para reorientar a formação na área da saúde 5 .

Os grupos de aprendizagem tutorial conformados pelo PET-Saúde compõem-se de três atores - o tutor, o preceptor e $\mathrm{o}$ aluno de graduação. Os tutores são professores das IES que devem realizar a supervisão docente-assistencial, dirigida aos profissionais da saúde e aos estudantes; os preceptores detêm a função primordial de supervisionar e orientar as ações dos alunos no serviço e aos alunos compete o desenvolvimento de atividades de pesquisa, sob orientação do tutor e do preceptor e de atividades de iniciação ao trabalho no campo da $\mathrm{ESF}^{4}$.

Na Universidade de São Paulo (USP), campus capital, o Programa foi iniciado em 2009, com participação de sujeitos ligados aos cursos de graduação em medicina, odontologia, enfermagem, terapia ocupacional, fisioterapia e fonoaudiologia. No ano seguinte, a proposta foi ampliada para os cursos de nutrição, psicologia, educação física e farmácia. Participaram no primeiro e no segundo período de vigência do Programa (2009 e 2010/2012), respectivamente, 8 e 10 professores de graduação, 48 e 60 profissionais de saúde inseridos na ESF e 96 e 120 estudantes.

O presente trabalho se propôs a obter uma opinião coletiva, qualificada e consensual de um grupo de conhecedores potenciais sobre o referido Programa.

O estudo se justifica ao oferecer subsídios para que iniciativas como essas sejam aprimoradas e convertidas em modelo inspirador para as ações de interação das IES com os serviços.

\section{Metodologia}

Utilizou-se uma abordagem qualitativa em que os sujeitos foram os tutores do PET-Saúde USP Capital que integraram o Programa no período 2010-2012.

Para coletar os dados, foi empregada a técnica Delphi. Ela possibilita, de forma rápida e eficiente, debater temas polêmicos, principalmente quando tempo e custo são fatores limitantes na promoção de encontros e conferências ou quando os desacordos podem ser minimizados pelo anonimato ${ }^{6}$. Trata-se de um processo estruturado mediado por uma série de questionários em rodadas, que aponta para a obtenção de uma opinião coletiva, qualificada e consensual sobre determinadas questões a partir de um grupo de pessoas selecionadas, geralmente conhecedoras potenciais de assuntos específicos. A técnica tem como pressuposto a ideia de que o julgamento coletivo é mais sólido que as opiniões fornecidas de forma individual ${ }^{7}$.

O instrumento mais utilizado nesse tipo de abordagem é o questionário. No momento de composição das questões, recorreu-se à literatura e estruturou-se o primeiro questionário composto por três questões discursivas. Para as duas rodadas subsequentes, foram confeccionados outros questionários, baseados nas respostas discursivas de todos os tutores.

Desenvolveu-se um sítio eletrônico, como proposto por Giovinazzo ${ }^{8}$, que hospedou os questionários, gradativamente e durante todo o processo de coleta de dados. No mesmo local, constava o Termo de Consentimento Livre e Esclarecido (TCLE) e informações gerais sobre a pesquisa e dados sobre as pesquisadoras.

Para iniciar a coleta de dados, foi feito um contato via correio eletrônico, por mensagem individual, em setembro de 2011, aos dez tutores que possuíam vínculo com o PET-Saúde USP Capital no recorte temporal estudado.

Após a devolução dos questionários dos oito tutores que se dispuseram a participar, as pesquisadoras fizeram a compilação e o agrupamento das respostas por eixos na expectativa de viabilizar a construção do questionário da segunda 
rodada. Surgiu a necessidade de inclusão de outra questão discursiva, de modo a elucidar indagações oriundas do primeiro questionário. Para se posicionar com relação às assertivas contidas no novo questionário, os participantes consideraram a escala de concordância Likert (1. Não concordo totalmente; 2 . Não concordo parcialmente; 3 . Indiferente; 4 . Concordo parcialmente e 5. Concordo totalmente), inserindo um código de avaliação para cada afirmação.

A pergunta presente no questionário da segunda rodada, que deveria ser respondida de maneira discursiva, também foi sintetizada e organizada por eixos que foram julgados pelos tutores por meio da escala Likert, na terceira rodada. Esta ocorreu no mês de abril de 2012, quando a coleta de dados foi finalizada, com sete questionários.

No sentido de evidenciar o grau de concordância alcançado pelo grupo de tutores, utilizouse uma adaptação do modelo desenvolvido por Esher et al. ${ }^{7}$

Para cada assertiva, após o julgamento realizado por meio da escala Likert, foi atribuído um valor que variava de 0 a 4 , crescente em função da concordância, como ilustrado no Quadro 1. À opção 'indiferente' foi concedido o valor '0', visto que as afirmativas avaliadas dessa maneira não se enquadram em um grau de concordância para elaboração de uma opinião consensual.

A pontuação final de cada assertiva foi calculada através da soma do resultado da multiplicação do número total de respostas pelo valor correspondente ao grau de concordância escolhido. Por exemplo, a primeira afirmação ilustrada no Quadro 1, recebeu uma resposta para 'concordo parcialmente', cujo valor é 3 e seis respostas para 'concordo totalmente', que corresponde ao valor 4. Nesse caso, a assertiva recebeu uma pontuação total de 27 pontos $(1 \times 3+6 \times 4=27)$.

O projeto foi aprovado pelo Comitê de Ética em Pesquisa da Secretaria Municipal de Saúde do município de São Paulo.

\section{Resultados e discussão}

A pontuação máxima possível de ser atingida por cada assertiva foi de 28 pontos e, no estudo, essa pontuação variou de 12 a 28 pontos. Considerou-se com alto grau de concordância (AC) as afirmações que obtiveram entre 22 e 28 pontos (acima de 79\% da pontuação total). Grau de concordância parcial (CP) foi atribuído às questões que pontuaram entre 17 e 21 pontos $(60 \%$ a $78 \%$ da pontuação total). As afirmações que atingi-

Quadro 1. Disponibilização das rodadas para condução da coleta de dados.

\begin{tabular}{|c|c|c|c|c|c|c|}
\hline \multicolumn{7}{|c|}{$\begin{array}{c}\text { Primeira Rodada } \\
03 \text { questões discursivas }\end{array}$} \\
\hline \multicolumn{7}{|c|}{$\begin{array}{c}\text { Segunda Rodada } \\
09 \text { eixos } \\
27 \text { assertivas } \\
03 \text { espaços para comentários livres } \\
01 \text { questão discursiva }\end{array}$} \\
\hline \multicolumn{7}{|c|}{$\begin{array}{c}\text { Terceira rodada } \\
05 \text { eixos } \\
34 \text { assertivas } \\
01 \text { espaço para comentário livre }\end{array}$} \\
\hline \multicolumn{7}{|c|}{ Modelo do quadro utilizado para manifestação do grau de concordância } \\
\hline Eixo & Assertiva & $\begin{array}{c}0 \\
\text { Indiferente }\end{array}$ & $\begin{array}{c}1 \\
\text { Não concordo } \\
\text { totalmente }\end{array}$ & $\begin{array}{c}2 \\
\text { Não concordo } \\
\text { parcialmente }\end{array}$ & $\begin{array}{c}3 \\
\text { Concordo } \\
\text { parcialmente }\end{array}$ & $\begin{array}{c}4 \\
\text { Concordo } \\
\text { totalmente }\end{array}$ \\
\hline Benefício & $\begin{array}{l}\text { Há benefícios em } \\
\text { participar do PET- } \\
\text { Saúde para a } \\
\text { atuação docente. }\end{array}$ & 0 & 0 & 0 & 1 & 6 \\
\hline
\end{tabular}


ram pontuações inferiores foram desconsideradas (D).

Os eixos, as assertivas correspondentes e a pontuação atribuída no somatório final encontram-se disponibilizados no Quadro 2.

As opiniões dos professores participantes do PET-Saúde USP Capital foram organizadas e discutidas, sequencialmente, de acordo com as questões e os eixos que foram disponibilizados nos questionários.

\section{Contribuições do contexto do trabalho na atuação docente}

Os novos enfoques teóricos e de produção tecnológica na área da saúde exigem a conformação de profissionais com características diferenciadas, em harmonia com as exigências do setor. A Norma Operacional Básica sobre Recursos Humanos em Saúde do SUS (NOB/RH-SUS) afirma ser imprescindível e obrigatório o comprometimento das instituições de ensino com o SUS e com o modelo assistencial vigente através, dentre outros requisitos, da implementação de política de capacitação de docentes orientada para o SUS ${ }^{9}$. No entanto, o que se observa é que as práticas pedagógicas estabelecidas na área da saúde se conservam sem grandes inovações ${ }^{10}$.

Ao longo de anos, se acreditou que o bom professor era representado pelo técnico competente. Mas, o ensino universitário exige uma capacitação própria e específica que não se restringe a ter um diploma de bacharel, ou de pós-graduação ou, ainda, o exercício da profissão em que se leciona ${ }^{11}$. Para romper com as estruturas cristalizadas do modelo tradicional de educação e contribuir para a formação de um novo perfil de profissionais de saúde, torna-se indispensável a reflexão sobre a reconstrução do perfil dos sujeitos formadores ${ }^{12}$.

Nesse sentido, os tutores concordaram que o PET-Saúde proporciona benefícios para a atuação docente. A participação no Programa estimula a reflexão sobre as práticas pedagógicas desenvolvidas nas unidades de ensino, contribuindo para torná-las adequadas no sentido de favorecer a formação demandada pelo SUS.

Os professores que integraram o PET-Saúde USP Capital afirmaram que a interação ensinoserviço induz a reflexões sobre as grades curriculares, contribuindo para torná-las mais coerentes com as necessidades do serviço e da população e, assim, adequando-as aos ideais da formação em saúde. Eles acreditam que ao se aproximar do mundo do trabalho em saúde, especifi- camente através do PET-Saúde, revelam-se desafios e limites inerentes ao contexto, o que subsidia o estabelecimento de um paralelo entre a teoria e a prática no processo de ensino-aprendizagem, tornando as práticas docentes condizentes com a realidade do trabalho em saúde.

Além disso, o Programa viabilizou a interação dos tutores com categorias profissionais distintas o que, geralmente, não ocorre nas unidades de ensino. Essa interação advém do contato com outros professores, com profissionais dos serviços de saúde e com alunos das diferentes áreas profissionais presentes no PET-Saúde USP Capital. Necessita-se de profissionais docentes preparados para desempenhar sua profissão de forma contextualizada e de maneira interdisciplinar ${ }^{11}$.

Infere-se, a partir dessas colocações, que o PET-Saúde se conforma como dispositivo relevante para a qualificação docente, contribuindo para as inovações pedagógicas na formação em saúde.

\section{Formação profissional voltada para a Atenção Básica}

Quando estimulados a refletir sobre como a relação aluno/preceptor contribui para a conformação de um perfil profissional voltado para a Atenção Básica, os tutores foram unânimes em explicitar que os preceptores facilitam o processo de aprendizagem e são de grande importância para fortalecer as atividades desenvolvidas. Os professores ligados ao PET-Saúde USP Capital imputam o sucesso que pode ser alcançado na formação à relação aluno/preceptor e esse resultado está diretamente ligado ao grau de afinidade existente entre eles. Ressaltam que o contato dos alunos com profissionais de categorias de formação diferenciadas revela novas realidades de atuação profissional.

Os tutores julgam que o aprofundamento e o estreitamento com o mundo do trabalho geram a ampliação do olhar do estudante sobre a realidade dos serviços, nos seus aspectos positivos e negativos, além de propiciar o conhecimento da futura prática profissional. Conclusões semelhantes foram explanadas por Souza-Neto et al. ${ }^{13}$, ao relatarem a experiência do PET-Saúde da Universidade Federal de Alagoas (UFAL). Ao se compartilhar os espaços de práticas em saúde com a academia, assegura-se um local privilegiado para a qualificação dos profissionais que atuam nos serviços. Nessa lógica, os preceptores também se beneficiam, enquanto profissionais, visto que a convivência com os alunos de gradu- 
Quadro 2. Eixos, assertivas e pontuação final do grau de concordância.

\begin{tabular}{|c|c|c|c|}
\hline EIXO & Assertiva & $\begin{array}{l}\text { Pontuação } \\
\text { final }\end{array}$ & $\begin{array}{l}\text { Grau de } \\
\text { concordância }\end{array}$ \\
\hline Benefício & $\begin{array}{l}\text { Há benefícios em participar do PET-Saúde para a atuação } \\
\text { docente. }\end{array}$ & 27 & $\mathrm{AC}$ \\
\hline $\begin{array}{l}\text { Práticas } \\
\text { docentes }\end{array}$ & $\begin{array}{l}\text { Ocorre o estímulo à reflexão sobre as práticas docentes, o } \\
\text { que gera contribuições no sentido de torná-las mais } \\
\text { adequadas. } \\
\text { Temáticas e objetos que precisam ser abordadas no ensino } \\
\text { ou investigados por meio de pesquisas são revelados. } \\
\text { A interação ensino/serviço induz a reflexões sobre as } \\
\text { grades curriculares, contribuindo para torná-las mais } \\
\text { coerentes com as necessidades do serviço e da população. }\end{array}$ & $\begin{array}{l}21 \\
22\end{array}$ & $\begin{array}{l}\mathrm{CP} \\
\mathrm{AC}\end{array}$ \\
\hline $\begin{array}{c}\text { Conhecimento } \\
\text { do contexto do } \\
\text { trabalho }\end{array}$ & $\begin{array}{l}\text { A atividade docente pode ser aprimorada se o } \\
\text { conhecimento do contexto do trabalho foi iniciado com a } \\
\text { participação no PET-Saúde, enquanto prática atrelada a } \\
\text { uma atividade acadêmica. } \\
\text { É capaz de evidenciar limites e desafios dos serviços de } \\
\text { saúde (específicos de cada área ou gerais). } \\
\text { Fornece subsídios para aprimorar a prática docente e } \\
\text { torná-la mais condizente com a realidade do trabalho em } \\
\text { saúde. } \\
\text { É capaz de propiciar uma maior interação } \\
\text { multiprofissional, tanto do ponto de vista docente } \\
\text { (oferecendo uma vivência entre tutores de distintas áreas } \\
\text { de ensino), quanto do ponto de vista do contato com } \\
\text { profissionais do serviço, das diversas áreas da saúde. } \\
\text { A experiência docente prévia no contexto do trabalho pode } \\
\text { contribuir para a participação do tutor no PET-Saúde. } \\
\text { A participação no PET-Saúde não contribui } \\
\text { necessariamente para o aprimoramento da atividade } \\
\text { docente, quando a imersão no contexto do trabalho já } \\
\text { existe no processo ensino-aprendizagem de algum curso de } \\
\text { graduação. }\end{array}$ & $\begin{array}{l}26 \\
27\end{array}$ & $\begin{array}{l}\mathrm{CP} \\
\mathrm{CP}\end{array}$ \\
\hline \multicolumn{4}{|c|}{$\begin{array}{l}\text { Questão } 2 \text { - Como você avalia a interação aluno/preceptor? De que modo a interação aluno/preceptor } \\
\text { oferece subsídios para a conformação de um perfil profissional voltado para atuação na Atenção Básica? }\end{array}$} \\
\hline EIXO & Assertiva & $\begin{array}{l}\text { Pontuação } \\
\text { final }\end{array}$ & $\begin{array}{l}\text { Grau de } \\
\text { concordância }\end{array}$ \\
\hline $\begin{array}{l}\text { Interação } \\
\text { aluno/ } \\
\text { preceptor }\end{array}$ & $\begin{array}{l}\text { Constitui-se no "ponto forte", "no ponto crítico" ou "no } \\
\text { cerne do trabalho do PET". } \\
\text { A qualidade dessa interação é que define o sucesso na } \\
\text { formação dos graduandos. } \\
\text { A interação pode gerar tanto resultados positivos como } \\
\text { negativos, a depender da afinidade entre eles. } \\
\text { Propicia o conhecimento de novas realidades profissionais, } \\
\text { tendo em vista que a categoria profissional de ambos, na } \\
\text { maioria das vezes, não é coincidente. }\end{array}$ & $\begin{array}{l}21 \\
23 \\
26 \\
27\end{array}$ & $\begin{array}{l}\text { CP } \\
\text { AC } \\
\text { AC }\end{array}$ \\
\hline
\end{tabular}


Quadro 2. continuação

\begin{tabular}{|c|c|c|c|}
\hline EIXO & Assertiva & $\begin{array}{l}\text { Pontuação } \\
\text { final }\end{array}$ & $\begin{array}{l}\text { Grau de } \\
\text { concordância }\end{array}$ \\
\hline Preceptoria & $\begin{array}{l}\text { O preceptor tem um papel facilitador no processo de } \\
\text { aprendizagem. } \\
\text { Essa aprendizagem ocorre de maneira heterogênea, numa } \\
\text { relação direta com o grau de experiência dos preceptores. }\end{array}$ & 28 & $\mathrm{AC}$ \\
\hline Subsídios & $\begin{array}{l}\text { Propicia o conhecimento da futura prática profissional } \\
\text { (comuns e específicas) e do aprofundamento e } \\
\text { estreitamento do aluno com o mundo do trabalho, gerando } \\
\text { a ampliação do olhar do estudante sobre a realidade do } \\
\text { serviço (nos aspectos positivos e negativos). } \\
\text { Esses futuros profissionais serão capazes de desenvolver um } \\
\text { trabalho em equipe e atuarão como agentes } \\
\text { transformadores das práticas de saúde. } \\
\text { Os preceptores também são beneficiados, visto que o } \\
\text { contato com os alunos de graduação induz a reflexão sobre } \\
\text { o seu próprio trabalho e desperta para a necessidade de } \\
\text { atualização. }\end{array}$ & 21 & $\begin{array}{l}\mathrm{CP} \\
\mathrm{CP}\end{array}$ \\
\hline \multicolumn{4}{|c|}{$\begin{array}{l}\text { Questão } 3 \text { - Você acha que a interação do ensino com o serviço, através do PET-Saúde, é capaz de } \\
\text { fortalecer e aperfeiçoar o SUS? }\end{array}$} \\
\hline EIXO & Assertiva & $\begin{array}{l}\text { Pontuação } \\
\text { final }\end{array}$ & $\begin{array}{l}\text { Grau de } \\
\text { concordância }\end{array}$ \\
\hline $\begin{array}{c}\text { Interação } \\
\text { ensino-serviço }\end{array}$ & $\begin{array}{l}\text { É importante que essa interação se torne } \\
\text { institucionalizada e não esteja sujeita a financiamentos } \\
\text { descontínuos. }\end{array}$ & 22 & $\mathrm{AC}$ \\
\hline $\begin{array}{l}\text { Fortalecimento } \\
\quad \text { do SUS }\end{array}$ & $\begin{array}{l}\text { A interação ensino/serviço é capaz de fortalecer o SUS. } \\
\text { Formam-se profissionais mais conscientes sobre a } \\
\text { realidade do sistema, menos preconceituosos e mais } \\
\text { dispostos a encarar os desafios que o SUS enfrenta na sua } \\
\text { construção. } \\
\text { Estimula-se a investigação por meio de pesquisas sobre } \\
\text { objetos e práticas vivenciadas, o que gera conhecimento } \\
\text { para o serviço. } \\
\text { Constitui relevância, ainda, o estabelecimento dos } \\
\text { espaços de práticas em saúde como cenários para } \\
\text { educação permanente. } \\
\text { É possivel apontar, ainda, benefícios a curto prazo ou } \\
\text { imediatos, devido ao fato de essa interação criar } \\
\text { questionamentos e reflexões que tendem a tencionar o } \\
\text { trabalho rotineiro e pouco criativo dos serviços de saúde, } \\
\text { estabelecendo, de fato, a construção do saber de forma } \\
\text { compartilhada. }\end{array}$ & $\begin{array}{l}21 \\
21\end{array}$ & $\begin{array}{l}\mathrm{CP} \\
\mathrm{CP}\end{array}$ \\
\hline $\begin{array}{l}\text { Espaço de } \\
\text { trabalho }\end{array}$ & $\begin{array}{l}\text { A interação ensino-serviço propicia o reconhecimento do } \\
\text { espaço de trabalho em saúde (Atenção Básica) como um } \\
\text { futuro local de atuação profissional. }\end{array}$ & 26 & $\mathrm{AC}$ \\
\hline
\end{tabular}


Quadro 2. continuação

Questão 4 - Como você avalia a relação tutor/preceptor-aluno (quantitativa e qualitativamente)? Quais são os limites e/ou facilidades no estabelecimento dessas relações?

\begin{tabular}{|c|c|c|c|}
\hline EIXO & Assertiva & $\begin{array}{c}\text { Pontuação } \\
\text { final }\end{array}$ & $\begin{array}{c}\text { Grau de } \\
\text { concordância }\end{array}$ \\
\hline $\begin{array}{l}\text { Relação tutor/ } \\
\text { preceptor- } \\
\text { aluno }\end{array}$ & $\begin{array}{l}\text { As relações são amigáveis e muito ricas. } \\
\text { Não existe uma hierarquia, nessas relações, capaz de } \\
\text { gerar prejuízos para o Programa. } \\
\text { O bom funcionamento dessas relações é fundamental } \\
\text { para o desenvolvimento do Programa. } \\
\text { A qualidade da interação entre os atores (todos) } \\
\text { depende da forma como cada grupo PET-Saúde foi } \\
\text { implementado. } \\
\text { A proporção do número de tutores é adequada para o } \\
\text { número de preceptores e alunos. } \\
\text { A proporção do número de preceptores é adequada para } \\
\text { o número de alunos. } \\
\text { A relação dos tutores com os preceptores ocorre de forma } \\
\text { mais frequente do que a relação dos tutores com os } \\
\text { alunos. } \\
\text { A relação dos tutores com os alunos nem sempre } \\
\text { acontece de maneira direta. }\end{array}$ & $\begin{array}{r}25 \\
26 \\
27 \\
24\end{array}$ & $\begin{array}{l}\mathrm{AC} \\
\mathrm{AC} \\
\mathrm{AC} \\
\mathrm{AC}\end{array}$ \\
\hline $\begin{array}{c}\text { Responsabilidades } \\
\text { da Tutoria }\end{array}$ & $\begin{array}{l}\text { Os tutores devem assistir e auxiliar os preceptores no } \\
\text { desenvolvimento das atividades programadas. } \\
\text { A tutoria possui um grande potencial para o manejo das } \\
\text { demandas de pesquisa e facilita a identificação dos } \\
\text { objetos. } \\
\text { O tutor representa a comunicação do serviço com o } \\
\text { universo acadêmico e suas linguagens. } \\
\text { A atuação dos tutores nos cenários de prática facilita a } \\
\text { interação entre preceptores e alunos e dos alunos entre si. } \\
\text { Os tutores possuem elementos para promover a } \\
\text { articulação da teoria com a prática e favorecer a } \\
\text { discussão acerca da formação e do trabalho } \\
\text { interdisciplinar em saúde. } \\
\text { A participação dos tutores na proposta do PET-Saúde } \\
\text { auxilia na avaliação crítica das práticas. }\end{array}$ & $\begin{array}{l}23 \\
22 \\
29\end{array}$ & $\begin{array}{l}\mathrm{AC} \\
\mathrm{AC} \\
\mathrm{AC}\end{array}$ \\
\hline $\begin{array}{c}\text { Responsabilidades } \\
\text { da Preceptoria }\end{array}$ & $\begin{array}{l}\text { Os preceptores devem acompanhar, de forma mais } \\
\text { próxima, as atividades desenvolvidas pelos estudantes. } \\
\text { Os preceptores devem fornecer um "feedback" aos } \\
\text { tutores sobre o desenvolvimento das atividades nos } \\
\text { campos de prática. } \\
\text { O preceptor é o responsável pelo controle das frequências } \\
\text { dos alunos. } \\
\text { O treinamento dos alunos para atuação em equipe } \\
\text { multidisciplinar demanda muito a ação do preceptor. }\end{array}$ & $\begin{array}{l}26 \\
26\end{array}$ & $\begin{array}{l}\mathrm{AC} \\
\mathrm{AC}\end{array}$ \\
\hline
\end{tabular}


Quadro 2. continuação

\begin{tabular}{|c|c|c|c|}
\hline EIXO & Assertiva & $\begin{array}{c}\text { Pontuação } \\
\text { final }\end{array}$ & $\begin{array}{c}\text { Grau de } \\
\text { concordância }\end{array}$ \\
\hline $\begin{array}{l}\text { Dispositivos } \\
\text { utilizados para } \\
\text { aprimorar a } \\
\text { relação tutor/ } \\
\text { preceptor- } \\
\text { alunos }\end{array}$ & $\begin{array}{l}\text { São realizadas reuniões regulares entre tutores e } \\
\text { preceptores para discussão dos projetos de forma conjunta } \\
\text { e sistematização das ações. } \\
\text { A realização de Seminários com apresentação das } \\
\text { atividades permite uma visão de conjunto do que se faz na } \\
\text { UBS no que se refere ao PET-Saúde. } \\
\text { Os diários de campo representam uma forma ainda pouco } \\
\text { explorada, mas muito adequada para avaliar atividades, } \\
\text { inclusive permitem registro de frequência. }\end{array}$ & 25 & AC \\
\hline Facilidades & $\begin{array}{l}\text { As reuniões entre o coordenador do programa, os tutores e } \\
\text { os gerentes das UBS subsidiam na condução dessas } \\
\text { relações. } \\
\text { Variação dos locais (UBS e IES) e dos horários das } \\
\text { reuniões periódicas pode favorecer a participação de todos } \\
\text { os atores. } \\
\text { Estudantes mais interessados e comprometidos facilitam o } \\
\text { desenvolvimento das atividades propostas. } \\
\text { Para as profissões que ainda não atuam nas equipes do } \\
\text { PSF, o PET é muito interessante para estudo de } \\
\text { possibilidades para participação futura. }\end{array}$ & $\begin{array}{l}28 \\
27\end{array}$ & $\begin{array}{l}\text { AC } \\
\text { AC }\end{array}$ \\
\hline Limites & $\begin{array}{l}\text { Alguns estudantes não são comprometidos com o } \\
\text { Programa. } \\
\text { A carga horária dos cursos de graduação é elevada, o que } \\
\text { gera indisponibilidade de horários comuns entre os } \\
\text { estudantes e as UBS e, consequentemente, dificuldades } \\
\text { para planejar e desenvolver atividades conjuntas. } \\
\text { Ocorre incompatibilidade de horários entre os estudantes e } \\
\text { os professores. } \\
\text { A triagem dos estudantes, feita pelas Unidades de Ensino, } \\
\text { não utiliza o rigor necessário para selecionar alunos com o } \\
\text { perfil demandando pelo PET-Saúde. } \\
\text { Se os tutores não cobram dos preceptores sob sua } \\
\text { supervisão um controle na execução das atividades } \\
\text { desenvolvidas pelos estudantes pode haver dificuldade na } \\
\text { realização das tarefas. } \\
\text { Algumas vezes, o gerente da Unidade exerce o papel de } \\
\text { tutoria. } \\
\text { A maior dificuldade é concretizar o PET-Saúde de forma } \\
\text { diferenciada dos estágios supervisionados. } \\
\text { Existe ausência de clareza e indefinição dos papéis do } \\
\text { tutor e do preceptor na organização das atividades do } \\
\text { programa. }\end{array}$ & $\begin{array}{l}20 \\
14 \\
12\end{array}$ & $\begin{array}{c}\mathrm{CP} \\
\mathrm{D} \\
\mathrm{D}\end{array}$ \\
\hline
\end{tabular}

ação induz a reflexão sobre o trabalho desenvolvido e desperta para a necessidade de atualização constante.

\section{Interação ensino-serviço como fortalecedora do SUS}

No quesito referente ao potencial da interação ensino-serviço, norteada pelo PET-Saúde, para o aperfeiçoamento e fortalecimento do SUS, 
os tutores enfocaram a necessidade de se institucionalizar essa interação para que ela não seja colocada em uma situação de instabilidade de financiamentos.

Quando se considera o SUS como formador, há que se pensar na responsabilidade pedagógica atribuída ao funcionário e de que maneira isso pode gerar algum diferencial ou não em sua carreira, visto que nem sempre haverá vantagem financeira em decorrência dessa atividade.

A interação ensino-serviço revela objetos de pesquisa nos espaços de produção de saúde, gerando conhecimento também para os serviços. Essa ligação, reforçando o que foi dito anteriormente, contribui para potencializar a educação permanente em saúde. Entretanto, a concordância parcial dos tutores nesse eixo revela o risco de se reduzir o potencial dessa vivência no contexto do trabalho em projetos de pesquisa de interesse docente.

É possível indicar benefícios em curto prazo ou imediatos, devido ao fato de essa interação criar questionamentos e reflexões que tendem a tencionar o trabalho rotineiro dos serviços de saúde, estabelecendo, de fato, a construção do saber de forma compartilhada.

Outra vantagem proporcionada é o reconhecimento do espaço de trabalho em saúde como um futuro local para a atuação profissional. Com relação às profissões que ainda não atuam nas equipes da ESF, o PET-Saúde se configura como um interessante instrumento para o estudo de possibilidades futuras.

\section{Relações e responsabilidades}

A problemática das relações entre os atores do Programa foi discutida na questão 04 . No entender dos sujeitos, as relações entre tutores e preceptores e entre tutores e alunos são "amigáveis" e "muito ricas”. Não há uma hierarquia rigidamente estabelecida, capaz de gerar prejuízos para o andamento do Programa. Os tutores asseveraram que a harmonia nessas relações foi fundamental para o desenvolvimento da proposta e que a qualidade dessa interação manteve dependência com a forma de implementação de cada um dos grupos PET-Saúde.

$\mathrm{Na}$ perspectiva dos professores, a proporção do número de tutores é adequada para o número de preceptores e alunos e a quantidade de preceptores é viável para conduzir as atividades com o grupo de estudantes. Cada um dos grupos de educação tutorial é composto por um tutor, seis preceptores e doze alunos de graduação.
No entanto, os professores que integraram o PET-Saúde USP Capital concordaram que a relação deles com os preceptores acontecia de forma mais frequente do que a relação dos tutores com os alunos, sendo que a motivação dos últimos favoreceu a interação, o que sinaliza a importância no processo seletivo. Ao explorar o processo de ensino-aprendizagem em sala de aula, Masetto ${ }^{11}$ comenta que a interação professor-aluno, tanto individualmente quanto com o grupo, se destaca e é fundamental no processo de aprendizagem. Mesmo cientes das diferenças existentes entre uma sala de aula convencional e o cenário de aprendizagem do PET-Saúde e das distinções entre os moderadores da aprendizagem em um e em outro caso (professores e alunos no processo ensino-aprendizagem em sala de aula e tutores, preceptores e alunos no PETSaúde), acredita-se que o tutor deve se colocar no papel de mediador pedagógico - processo que considera o professor como facilitador, incentivador e motivador do processo de aprendizagem - somando esforços com os preceptores na construção do conhecimento por meio da dinâmica do PET-Saúde. O ideal é que as relações se estabeleçam mutuamente.

Na peculiaridade do PET-Saúde, ao inserir um novo integrante no processo de aprendizagem - o preceptor - a mediação pedagógica é exercida, em diversos momentos, pelos trabalhadores dos serviços de saúde. Ao compreender as diferenças existentes entre o preparo pedagógico dos profissionais do serviço e dos professores universitários, se torna evidente a necessidade de acompanhamento de todas as atividades desenvolvidas pelo professor.

É notória, todavia, a fragilidade do vínculo estabelecido com o tutor na condução do Programa, possivelmente em decorrência da ausência de especificações claras referentes às atribuições pertinentes a ele e da sobrecarga de atividades de docência. Além disso, existe certo constrangimento para o tutor se manter inserido na rotina da Unidade Básica de Saúde (UBS), visto que ele não é funcionário do serviço.

Com relação às responsabilidades inerentes aos tutores, os sujeitos do estudo certificam que eles:

- Possuem grande potencial para o manejo das demandas de pesquisa e facilitam a identificação dos objetos de investigação;

- Representam a comunicação do serviço com o universo acadêmico e suas linguagens;

. Facilitam a interação entre preceptores e alunos e a interação dos alunos entre si; 
- Possuem elementos para promover a articulação da teoria com a prática e favorecer a discussão acerca da formação e do trabalho interdisciplinar em saúde;

- Auxiliam na avaliação crítica das práticas.

Os tutores fizeram menções ao papel desempenhado pelos preceptores para o desenvolvimento da proposta, sendo que eles:

. Devem acompanhar, de forma mais próxima, as atividades desenvolvidas pelos estudantes;

. Devem oferecer um "feedback" aos tutores sobre o desenvolvimento das atividades nos campos de prática;

. São os responsáveis pela atribuição das frequências dos alunos.

- São imprescindíveis para preparar os alunos e qualificá-los de forma a atuar em equipes multidisciplinares;

Existem alguns dispositivos utilizados para aprimorar e estreitar a relação entre os atores do PET-Saúde USP Capital. Segundo os tutores, são planejadas e desenvolvidas reuniões regulares entre tutores e preceptores para discussão dos projetos e sistematização das ações. Além disso, seminários são organizados para proporcionar uma visão de conjunto do que se faz na UBS com a participação de todos os membros. Ambos objetivam discutir e subsidiar o planejamento das ações para torná-las mais adequadas. Corroborando com esses achados, a utilização de reuniões periódicas foram relatadas pelo PET-Saúde da UFAL ${ }^{13}$ e pelo PET-Saúde da Universidade de Santa Cruz do Sul (UNISC) ${ }^{14}$. Além disso, os tutores acreditam que os diários de campo, apesar de serem pouco explorados, representam um instrumento de avaliação das atividades e permitem o registro das frequências.

Os professores elencaram como facilidades para auxiliar na condução dessas relações os horários e locais variados para a realização das reuniões periódicas, no intuito de favorecer a participação de todos os atores. Eles admitem que o grau de interesse dos estudantes pelas atividades propostas também constitui um facilitador, sobretudo na relação aluno/preceptor. Para as profissões que ainda não estão inseridas na ESF, o Programa é interessante para o estudo de uma inserção futura.

Contrariamente, os limites apontados se referem à falta de comprometimento manifestada por alguns estudantes e a carga horária dos cursos de graduação que, no entender dos tutores, é elevada e gera indisponibilidade de horários co- muns entre os estudantes e as UBS, ocasionando dificuldades para planejar e desenvolver atividades conjuntas. De forma convergente, a investigação feita por Oliveira e Coelho ${ }^{15}$ com alunos do PET-Saúde da Universidade Federal do Mato Grosso do Sul (UFMS), apontou a incompatibilidade entre os horários dos participantes como a dificuldade mais relevante para operacionalizar efetivamente o Programa.

\section{Considerações finais}

Os resultados do estudo traduzem o PET-Saúde como um poderoso instrumento de indução de mudanças na concepção dos profissionais de saúde e na qualificação de professores dos cursos de graduação e trabalhadores dos serviços, contribuindo para a formação humanística, crítica e reflexiva almejada pelas Diretrizes Curriculares Nacionais para os cursos de graduação em saúde. Essa potencialidade advém, sobretudo, do caráter de integração ensino-serviço interdisciplinar, proporcionando reflexões abrangentes, capazes de inovar nas práticas pedagógicas e nas ações das UBS.

As relações estabelecidas entre os tutores, os preceptores e os estudantes devem ser fortalecidas e mantidas de forma mútua. É ideal que se busque alternativas e estratégias para fortalecer e contornar as limitações que dificultam o estabelecimento desses vínculos, especialmente, a ligação dos tutores com os alunos.

$\mathrm{O}$ estudo apontou algumas atribuições para os tutores e os preceptores, além de mostrar limites e facilidades na operacionalização do programa. Esses dados se mostram relevantes para aperfeiçoar o PET-Saúde, no recorte estudado e em nível nacional, uma vez que a documentação que regulamenta o Programa é vaga e superficial nesse aspecto, pois reconhece as diversidades de cenários e realidades das instituições, o que permite que cada grupo construa seu percurso. Entretanto, teme-se que essa abertura minimize o potencial de formação pelo trabalho.

É essencial viabilizar estratégias de organizações curriculares que disponibilizem horários para que os estudantes possam desempenhar as atividades nas UBS. Além disso, deve-se pensar no preparo pedagógico dos preceptores, uma vez que eles desempenham o papel de mediadores do processo de aprendizagem e representam grande importância para o sucesso do Programa. 


\section{Colaboradores}

GS Fonsêca e SR Junqueira trabalharam juntas na elaboração, execução e redação do trabalho.

\section{Referências}

1. Costa ICC, Araújo MNT. Definição do perfil de competências em saúde coletiva a partir da experiência de ciru rgiões-dentistas atuantes no serviço público. Cien Saude Colet 2011; 16(Supl. 1):1181-1189.

2. Garcia RA, Carvalho SR. Navegando no entre das instituições de ensino e serviços de saúde: uma carta náutica dos (des) encontros. In: Carvalho SR, Ferigato S, Barros ME, editores. Conexões: Saúde Coletiva e Políticas de Subjetividade. São Paulo: Hucitec; 2009. p. 220-239.

3. Mattos PES; Tomita NE. A inserção da saúde bucal no Programa Saúde da Família: da universidade aos pólos de capacitação. Cad Saude Publica 2004; 20(6):1538-1544.

4. Brasil. Ministério da Saúde (MS). Ministério da Educação (ME). Portaria Interministerial no. 1802 de 26 de agosto de 2008. Institui o Programa de Educação pelo Trabalho para a Saúde. Diário Oficial da União 2008; 27 ago.

5. Brasil. Ministério da Saúde (MS). Secretaria de Gestão do Trabalho e da Educação na Saúde. Edital no 18 , de 16 de semtebro de 2009. Seleção para o Programa de Educação pelo Trabalho para a Saúde - PET-SAÚDE. Diário Oficial da União 2009; 17 set.

6. Rowe G. Delphi: A revaluation of research and theory. Thechnological Forecasting and Social Changes 1991; 39(3):235-251.

7. Esher A, Santos EM, Magarinos-Torres R, Azeredo TB. Construindo critérios de julgamento em avaliação: especialistas e satisfação dos usuários com a dispensação do tratamento do HIV/AIDS. Cien Saude Colet 2012; 17(1)203-214.

8. Giovinazzo RA. Modelo de aplicação da metodologia Delphi pela internet: vantagens e ressalvas. Rev Adm on line [periódico na Internet]. 2001[acessado 2011 maio 5];2(2). Disponível em: http:// www.fecap.br/adm_online/art22/renata.htm.

9. Brasil. Ministério da Saúde (MS). Conselho Nacional de Saúde. Princípios e diretrizes para a gestão do trabalho no SUS (NOB/RH-SUS). 3a ed. Brasília: MS; 2005. (Série J. Cadernos)

10. Castanho ME. Professores de Ensino Superior da área da Saúde e sua prática pedagógica. Interface (Botucatu) 2002; 6(10):51-61.

11. Masetto MT. Competência pedagógica do professor universitário. São Paulo: Summus; 2003.

12. Péret ACA, Lima MLR. A pesquisa e a formação do professor de Odontologia nas políticas internacionais e nacionais de educação. Rev. ABENO 2003; 3(1):65-69.

13. Souza-Neto ACS, Almeida AL, Santos-Júnior PR, Novaes IM. Vivência da odontologia no PET- Saúde da Família da UFAL. Aprendizado de ações coletivas baseado no ensino-pesquisa-extensão acadêmicos. Rev. ABENO 2011; 11(1):16-18.

14. Borges TS, Daronco A, Silveira CS, Sonda EC, Marques BB, Battisti F, Pimentel C, Machado H, Rauber A, Santos MMB, Possuelo LG. PET-Saúde/Vigilância - UNISC: A relação com o ensino odontológico. Rev. ABENO 2011; 11(1):35-38. 
15. Oliveira ML, Coelho TC. A percepção de acadêmicos de odontologia sobre o PET-Saúde UFMS/SESAU, Campo Grande/MS, 2009. Rev. ABENO 2011; 11(1):76-80.

Artigo apresentado em 15/03/2013

Aprovado em 20/04/2013

Versão final apresentada em 15/05/2013 